EDITORIAL

\title{
Safety of Adeno-associated virus-based vector-mediated gene therapy-impact of vector dose
}

(c) The Author(s), under exclusive licence to Springer Nature America, Inc. 2021

Cancer Gene Therapy (2022) 29:1305-1306; https://doi.org/10.1038/ s41417-021-00413-6

Gene therapy has become a realistic option for the treatment of various genetic diseases [1]. It involves the use of a vector (viral/ non-viral) to deliver the required transgene for augmentation or correction of gene function [2]. Viral vectors have taken the center stage in gene therapy applications due to their evolutionarily fine-tuned ability to infect host tissue/cells [3]. Adeno-associated virus (AAV) [4] based vectors, being relatively safe $[5,6]$ have been evaluated in several clinical trials $(n=263$, date of access $28^{\text {th }}$ October 2021) (https://clinicaltrials.gov/). AAV based products such as Luxturna ${ }^{\odot}$ and Zolgensma ${ }^{\odot}$ have been approved by the US Food and Drug Administration (FDA) for the treatment of Leber congenital amaurosis type 2 (LCA2) and spinal muscular atrophy (SMA) [7] apart from several others that are available or in pipe-line [7]. Beside these successful attempts, some safety concerns have also emerged due to the mortality reported in a phase 2 clinical trial of a rare neuromuscular disease [8]. The etiology of such severe adverse events [9] in clinical settings and the basis of vector-related cytotoxicity [10], needs to be understood in toto.

To design an optimal gene transfer approach for a particular disease, a thorough understanding of the clinical data available with respect to safety and efficacy is essential. Herein, we have analyzed the retrospective and published data available from completed/ ongoing AAV-based clinical trials (https://clinicaltrials. gov/). We compared the clinical studies with respect to the disease targeted, route of vector delivery, dose administered, number of patients, adverse events, and major outcomes reported (Supplementary Table S1). While analyzing the data from clinical trials involving systemic vector administration, the target diseases included hemophilia A and hemophilia B, alpha-1 antitrypsin (AAT) deficiency, SMA, and lipoprotein lipase deficiency. Different AAV serotypes (AAV1, AAV2, AAV5, AAV8, and AAV9) have been used for gene therapy of these inherited disorders at vector doses ranging from $2 \times 10^{11}$ to $2 \times 10^{14}$ vector genomes per kilogram $(\mathrm{vgs} / \mathrm{kg})$ per patient. There is also an evidence for dose-dependent manifestation of the adverse events. In one of the first reports, at a lower dose $\left(2 \times 10^{11} \mathrm{vgs} / \mathrm{kg}\right)$ of AAV2-Factor IX vector, mild adverse events like increased neutralizing antibody titres was noted in hemophilia B patients, but a CD8+T-cell response against the capsid and increased liver transaminases were noted at a higher dose of $2 \times 10^{12} \mathrm{vgs} / \mathrm{kg}$ (Supplementary Table S1). In case of AAT deficiency, vector dose ranging from $6 \times 10^{11}$ to $6.9 \times 10^{13} \mathrm{vgs} / \mathrm{kg}$ generated a neutralizing antibody response and T-cell response while the phenotypic outcome was sub-therapeutic (Supplementary Table S1). For treatment of SMA, AAV9 vectors were used at a dose of $6.7 \times 10^{13}-2 \times 10^{14} \mathrm{vgs} / \mathrm{kg}$, which led to a mild elevation in liver transaminase but led to improved survival and motor function, after gene therapy (Supplementary Table S1).
For localized gene therapy involving the delivery of the vector directly into the affected organ, diseases pertaining to eye/retina (retinoschisis, X-linked retinitis pigmentosa, LCA2, choroideremia), heart (cardiac failure), muscle (muscular dystrophy), and brain (Parkinson's) have been targeted with a vector dose ranging between $1 \times 10^{9}$ and $1 \times 10^{13}$ vgs/patient. Ocular diseases (retinoschisis, $\mathrm{X}$-linked retinitis pigmentosa, LCA2, choroideremia) have been majorly treated via AAV2 or AAV8 serotype-based vectors $\left(1 \times 10^{9}-1 \times 10^{12} \mathrm{vgs} / \mathrm{eye}\right)$. While at the lower doses of $1 \times$ $10^{9}-1 \times 10^{10}$ vgs/eye, none to only mild adverse events were noted, at higher doses $\left(1 \times 10^{11}-1 \times 10^{12} \mathrm{vgs} / \mathrm{eye}\right)$ adverse events like inflammation and antibodies against AAV capsid with substantial improvement in the phenotypic outcomes were observed (Supplementary Table S1). In case of heart failure, AAV1 has been employed so far within a dose range of $1.4 \times$ $10^{11}-1 \times 10^{13} \mathrm{vgs} /$ patient. The outcome data showed no significant adverse events when vectors were given to patients at lower doses $\left(1.4 \times 10^{11} \mathrm{vgs} /\right.$ patient), while a patient who had received AAV1-SERCA2a vectors at the higher dose of $1 \times 10^{13} \mathrm{vgs} /$ patient had a neutralizing antibody response (Supplementary Table S1). In patients with Becker and Duchenne muscular dystrophy, AAV1 and mutant AAV2 capsids have been used $(6 \times$ $10^{11}-3 \times 10^{12} \mathrm{vgs} /$ patient) causing no major adverse events, with an exception of neutralizing antibodies against AAV2 mutant capsid, along with an improvement in the phenotypic outcomes such as walking ability (Supplementary Table S1). In Parkinson's disease, rAAV2-hAADC, AAV-GAD, or rAAV2-Neurturin vectors when administered within a dose range of $5 \times 10^{9}-4.7 \times 10^{12} \mathrm{vgs} /$ patient, had no significant adverse events (mild neutralizing antibodies only) with a dose-dependent improvement in the phenotypic outcomes, except in one study [11] (Supplementary Table S1).

Taken together, these data highlight that gene therapy is relatively safe in diseases that require either localized/systemic delivery and at a lower threshold of vector dose administered $\left(\leq 10^{12} \mathrm{vgs} / \mathrm{kg} /\right.$ patient). However, further long-term follow-up data is required and as this information becomes available from the present clinical trials, a comprehensive understanding of the safety of AAV-based gene transfer will emerge. The efficacy of $A A V$ vectors in these clinical trials was also largely dosedependent [7] with the outcomes varying significantly based on the disease and serotype employed. Few preclinical studies on dog and mouse models have reported integration of recombinant $A A V$ vector transgene into the host genome leading to clonal expansion [12] and other adverse events $[13,14]$ but this has not been observed in humans thus far. Nonetheless, establishing a more robust dose-response relationship during pre-clinical gene therapy and assessment of potential genotoxicity with the use of optimal viral vectors $[15,16]$ may further improve the safety and efficacy of AAV gene therapy in humans. 
Shubham Maurya (D) $^{1,2}$, Pratiksha Sarangi ${ }^{1,2}$ and Giridhara R. Jayandharan (1D)

${ }^{1}$ Department of Biological Sciences and Bioengineering and The Mehta Family Centre for Engineering in Medicine, Indian Institute of Technology Kanpur, Kanpur, India. ${ }^{2}$ These authors contributed equally: Shubham Maurya, Pratiksha Sarangi ${ }^{\bowtie}$ email: jayrao@iitk.ac.in

\section{REFERENCES}

1. Dunbar CE, High KA, Joung JK, Kohn DB, Ozawa K, Sadelain M. Gene therapy comes of age. Science. 2018;359:eaan4672.

2. Singh V, Khan N, Jayandharan GR. Vector engineering, strategies, and targets in cancer gene therapy. Cancer Gene Ther. 2021. https://doi.org/10.1038/s41417021-00331-7.

3. Bulcha JT, Wang Y, Ma H, Tai PWL, Gao G. Viral vector platforms within the gene therapy landscape. Signal Transduct Target Ther. 2021;6:53.

4. Atchison RW, Casto BC, Hammon WM. Adenovirus-associated defective virus particles. Science 1965;149:754-6.

5. Mingozzi F, High KA. Immune responses to AAV vectors: overcoming barriers to successful gene therapy. Blood 2013;122:23.

6. Balakrishnan B, Jayandharan G. Basic biology of adeno-associated virus (AAV) vectors used in gene therapy. Curr Gene Ther. 2014;14:86-100. 2

7. Shahryari A, Saghaeian Jazi M, Mohammadi S, Razavi Nikoo H, Nazari Z, Hosseini ES, et al. Development and clinical translation of approved gene therapy products for genetic disorders. Front Genet. 2019;10:868.

8. Agarwal S. High-dose AAV gene therapy deaths. Nat Biotechnol. 2020;38:910

9. Day JW, Finkel RS, Chiriboga CA, Connolly AM, Crawford TO, Darras BT, et al. Onasemnogene abeparvovec gene therapy for symptomatic infantile-onset spinal muscular atrophy in patients with two copies of SMN2 (STR1VE): an openlabel, single-arm, multicentre, phase 3 trial. Lancet Neurol. 2021;20:284-93.

10. Flotte TR, Trapnell BC, Humphries M, Carey B, Calcedo R, Rouhani F, et al. Phase 2 clinical trial of a recombinant adeno-associated viral vector expressing alpha1antitrypsin: interim results. Hum Gene Ther. 2011;22:1239-47.

11. Marks WJ Jr, Bartus RT, Siffert J, Davis CS, Lozano A, Boulis N, et al. Gene delivery of AAV2-neurturin for Parkinson's disease: a double-blind, randomised, controlled trial. Lancet Neurol. 2010;9:1164-72.

12. Nguyen GN, Everett JK, Kafle S, Roche AM, Raymond HE, Leiby J, et al. A long-term study of AAV gene therapy in dogs with hemophilia A identifies clonal expansions of transduced liver cells. Nat Biotechnol. 2021;39:47-55.

13. Dalwadi DA, Torrens L, Abril-Fornaguera J, Pinyol R, Willoughby C, Posey J, et al. Liver injury increases the incidence of HCC following AAV gene therapy in mice. Mol Ther. 2021;29:680-90.
14. Li Y, Miller CA, Shea LK, Jiang X, Guzman MA, Chandler RJ, et al. Enhanced efficacy and increased long-term toxicity of CNS-directed, AAV-based combination therapy for Krabbe disease. Mol Ther. 2021;29:691-701.

15. Maurya S, Mary B, Jayandharan GR. Rational engineering and preclinical evaluation of neddylation and SUMOylation site modified adeno-associated virus vectors in murine models of hemophilia $B$ and Leber congenital amaurosis. Hum Gene Ther. 2019;30:1461-76.

16. Li C, Samulski RJ. Engineering adeno-associated virus vectors for gene therapy. Nat Rev Genet. 2020;21:255-72.

\section{ACKNOWLEDGEMENTS}

The authors thank Ms. Vijayata Singh, Molecular Genetics and Therapeutics laboratory, BSBE, IIT-Kanpur for the review of the manuscript. GRJ is supported inpart from ASPIRE research award from Pfizer, Inc. USA (\#5359919). SM and PS were supported by a Ph.D. fellowship (MHRD grant to IIT-Kanpur).

\section{AUTHOR CONTRIBUTIONS}

SM, PS, and JGR analyzed data and wrote the manuscript. All the authors participated in a critical review of the manuscript and contributed to the final manuscript product.

\section{CONFLICT OF INTEREST}

The authors declare that IIT-Kanpur has filed non-provisional patents on improved $A A V$ vectors for gene delivery.

\section{ADDITIONAL INFORMATION}

Supplementary information The online version contains supplementary material available at https://doi.org/10.1038/s41417-021-00413-6.

Correspondence and requests for materials should be addressed to Giridhara R. Jayandharan.

Reprints and permission information is available at http://www.nature.com/ reprints

Publisher's note Springer Nature remains neutral with regard to jurisdictional claims in published maps and institutional affiliations. 